\title{
Contra el viento: regulación, crisis social y cambio institucional en el Corredor Eólico del Istmo
}

\section{Against the wind: regulation, social crisis and institutional change in the Wind Corridor in the Isthmus}

\author{
Miriam Grunstein Dickter*
}

\begin{abstract}
This article analyzes the regulatory deficiencies that have caused and aggravated social conflict between two groups: the rural inhabitants and the electric developers in Oaxaca's Istmo de Tehuantepec. In this sense, this article recommends the need to review the institutional framework of private electric projects in Mexico, in order to include a valuation of their social impact. To illustrate this point, the case of Gas Natural Fenosa's, Bii Hioxo will be examined in order to demonstrate this institutional collision. Last, an analysis is made on how the 2013 energy reform could have helped solve such conflicts but failed to do so.
\end{abstract}

Keywords: electric self-sufficiency, public service, institutional change, community presence, regulatory barriers and Gas Natural Fenosa.

\section{Resumen}

En este artículo se analizan las fallas de regulación que agravan el conflicto entre los habitantes rurales y las empresas desarrolladoras del proyecto eólico de Gas Natural Fenosa (GNF), Bií Hioxo en el Istmo de Tehuantepec, Oaxaca. El objetivo de esta investigación es demostrar los efectos, principalmente sociales, así como las fallas institucionales que impiden una evolución normativa que proponga beneficios para las comunidades en las que habrán de instalarse estas empresas. Finalmente, se hace un análisis de cómo la reforma energética de 2013, podría resolver el conflicto citado sin que este cambio normativo lo haya logrado.

Palabras clave: autoabastecimiento eléctrico, servicio público, cambio institucional, inclusión comunitaria, barreras regulatorias y Gas Natural Fenosa.

*Universidad Autónoma de Nuevo León, México. Correo-e: Miriam.grunsteind@uanl.mx 


\section{Introducción}

En esta investigación se analiza y demuestran las fallas de regulación que agravaron la crisis social entre los habitantes rurales y una empresa operadora del Corredor Eólico del Istmo de Tehuantepec, Oaxaca. ${ }^{1}$ Aun cuando casos como éste han sido ampliamente explorados desde la perspectiva del "abuso empresarial" en perjuicio de los derechos patrimoniales y humanos de los pobladores de dicha zona (De la Vega-Navarro, 2011), no existe aún un trabajo que ahonde en la cuestión de las insuficiencias regulatorias que dispararon y que han agudizado esta crisis. El caso, además de ser importante por sí mismo, resalta cuestiones ya identificadas por organismos públicos y privados, pero escasamente analizadas con profundidad. Se trata de las barreras de entrada a los proyectos de infraestructura de energías renovables que dimanan de la inmadurez y ambivalencia aún presentes en su marco de regulación.

La aceptabilidad de los proyectos de infraestructura suele ser una cuestión que implica conflictos de varias índoles, ya sean sociales, ambientales o políticas (Stigka et al., 2014). Más allá de la oposición llana a la instalación de infraestructura eléctrica en una zona geográfica y en una comunidad determinada (Bidwell, 2013), (Groth y Vogt, 2014), también es necesario comprender si se trata de un rechazo social generalizado a todo proyecto de generación eléctrica, al tipo de energía generada o a la naturaleza de sus beneficiarios (Baxter et al., 2013).

Por ejemplo, en un análisis de casos australianos, Hall et al. (2013) hallaron que una de las formas de consolidar el apoyo de las comunidades a los proyectos de generación con energías renovables se basa en cuatro factores: construir confianza, respetar nociones de justicia distributiva y procedimental y considerar el grado de apego de los agricultores a sus terrenos. A su vez, es importante subrayar que, en la medida en que la decisión de instalar un parque eólico implique mejores condiciones de vida para las comunidades, (Sutherland y Holstead, 2014) habrá mejores posibilidades de que su percepción sea positiva.

En este trabajo se hará una evaluación sobre si estos factores e incentivos fueron ponderados en la instalación de proyectos eólicos en el Istmo de Tehuantepec. La hipótesis planteada en este análisis es que ni las autoridades ni los desarrolladores tomaron en cuenta estas variables.

${ }^{1}$ La mayoría de los habitantes de la zona ubicada en el Istmo de Tehuantepec está organizada en grupos comunales y ejidales; en este sentido, en Oaxaca las comunidades indígenas han ejercido a lo largo de los siglos su propia forma de gobierno, conocida como "usos y costumbres". Por ello, ante la construcción de los aerogeneradores, es evidente encontrar la oposición de los habitantes, ya que para ellos "la tierra es su madre", es de "donde vienen" y a quien "tienen que proteger" (Colectivo KoLibrI, 2013). 
Así, uno de los puntos focales de este artículo versa sobre las dificultades específicas que enfrenta la figura del autoabastecimiento eléctrico, establecido en el artículo 3 de la abrogada Ley del Servicio Público de la Energía Eléctrica (LSPEE), la cual no forma parte del Servicio Público, por estar éste reservado a la nación mexicana a través de la Comisión Federal de Electricidad (CFE). ${ }^{2}$ Esta figura es importante porque, siendo la más socorrida para la implementación de estos proyectos de generación eléctrica, por su propio estatuto jurídico no puede destinarse a la prestación del servicio a las comunidades.

En suma, el autoabastecimiento es una modalidad de generación eléctrica cuyo objetivo primario es la satisfacción de las necesidades de consumo de sus dueños, independientemente de las necesidades de la población donde estén situadas. ${ }^{3}$ Así, en el contexto actual de la reforma del sector eléctrico, una de las reflexiones aquí plasmadas sería si el nuevo marco jurídico ofrece a estos proyectos una nueva figura que mejore su inserción en estas comunidades.

Para el desarrollo de este trabajo se hizo un análisis jurídico a nivel nacional, que parte de una lectura crítica de los principales instrumentos de regulación, como los planes de desarrollo, leyes y reglamentos aquí citados, a la luz de los acontecimientos sociales que sucedieron a partir de su aplicación. Para entender estos últimos, se llevaron a cabo entrevistas a funcionarios de la Subsecretaría de Electricidad ahora responsables de la implementación de estos proyectos, ${ }^{4}$ a la par se llevó a cabo una investigación documental sobre las reacciones de las comunidades indígenas a los mismos.

Parte de esa investigación documental incluyó la pesquisa de notas periodísticas de la prensa nacional y extranjera, para dar cuenta de los acontecimientos de resistencia social en torno a los proyectos eólicos. ${ }^{5}$ También, se realizó una entrevista con funcionarios de Gas Natural Fenosa ${ }^{6}$ para recabar sus opiniones sobre las dificultades que ha enfrentado la implantación del corredor eólico Bií Hioxo.

\footnotetext{
${ }^{2}$ A su vez, el artículo 7 de la LSPEE (1975) dice: "La prestación del servicio público de energía eléctrica que corresponde a la Nación, estará a cargo de la Comisión Federal de Electricidad, la cual asumirá la responsabilidad de realizar todas las actividades a que se refiere el artículo 4”.

3 Según el artículo 36 de la LSPEE (1975) mediante el autoabastecimiento se genera la "energía eléctrica destinada a la satisfacción de necesidades propias de personas físicas o morales... La sociedad permisionaria no podrá entregar energía eléctrica a terceras personas físicas o morales que no fueren socios de la misma al aprobarse el proyecto original que incluya planes de expansión, excepto cuando se autorice la cesión de derechos o la modificación de dichos planes..." (Las cursivas son mías).

${ }^{4}$ Los cuestionamientos de las entrevistas se realizaron a partir de preguntas cerradas; se llevaron a cabo tres en total, en julio y agosto de 2013.

5 A partir de la cual se ubicaron alrededor de 30, con las voces "Corredor Eólico del Istmo", "Asamblea Popular de los Pueblos Juchitecos", "Resistencia a proyectos eólicos", "Conflicto social en Oaxaca", "Conflicto Gas Natural Fenosa Oaxaca”.

${ }^{6}$ Dicha entrevista fue cerrada, se llevó a cabo en octubre de 2013.
} 
Este trabajo se divide en tres secciones: en primer lugar se presentará el contexto de México en materia de desarrollo de energías renovables enfocado en la eólica. En la segunda sección, se analizarán las posibles implicaciones de la reforma energética de 2013. En el tercer apartado se esbozará el marco teórico conceptual empleado para el presente estudio. Finalmente, se analizarán las barreras de entrada para los desarrolladores de la infraestructura eólica bajo la aplicación de este marco teórico y se estudiará el caso particular de Bii Hioxo.

\section{Las energías renovables en México. Una introducción difícil}

La generación de energía eléctrica, a partir de fuentes renovables, se ha abierto paso en una brecha incipiente y precaria en México. En términos generales, se debe a dos razones preponderantes: por una parte, México es un país petrolero, cuya generación eléctrica depende, casi totalmente, de los combustibles fósiles; y por otra, debido a que el consumo de combustibles de la industria energética radica en la dinámica cerrada entre Petróleos Mexicanos (Pémex, el monopolio que vende combustibles fósiles) y CFE (el monopolio eléctrico que los compra).

En este sentido, las energías renovables son motivos de discrepancia entre el dúo del que tiene que abastecer hidrocarburos y aquel que tiene que generar con ellos. En este espacio limitado, de todas las energías renovables, descontadas las hidroeléctricas, es la energía eólica la que tiene mayor capacidad instalada en este país. En estudios del Instituto de Investigaciones Eléctricas se señala que el potencial eólico de México podría soportar una capacidad de generación eléctrica de $5000 \mathrm{MW}$, cercana a $10 \%$ de la capacidad total de generación que tiene actualmente el país (Borja-Díaz, 2003).

Si bien los espacios para la energía eólica son limitados, por los intersticios que deja el diseño legal de la industria energética en México, tal no es el caso de su potencial físico. Más aún, de entre las entidades de la Federación mexicana, en el estado de Oaxaca, en particular en el Istmo de Tehuantepec, existe uno de los mayores potenciales de generación de energía eólica, toda vez que su capacidad anual es suficiente para abastecer a 18 millones de usuarios. Esto se debe a que aquél se localiza en la parte más angosta de la república mexicana, por lo que el viento queda atrapado en una corriente (mapa 1), lo que trae como resultado que la velocidad anual de los vientos exceda los $10 \mathrm{~m} / \mathrm{s}$, cuando en promedio en otras partes del mundo únicamente se llegan a aprovechar vientos de $6,5 \mathrm{~m} / \mathrm{s}$ para la generación de energía. 


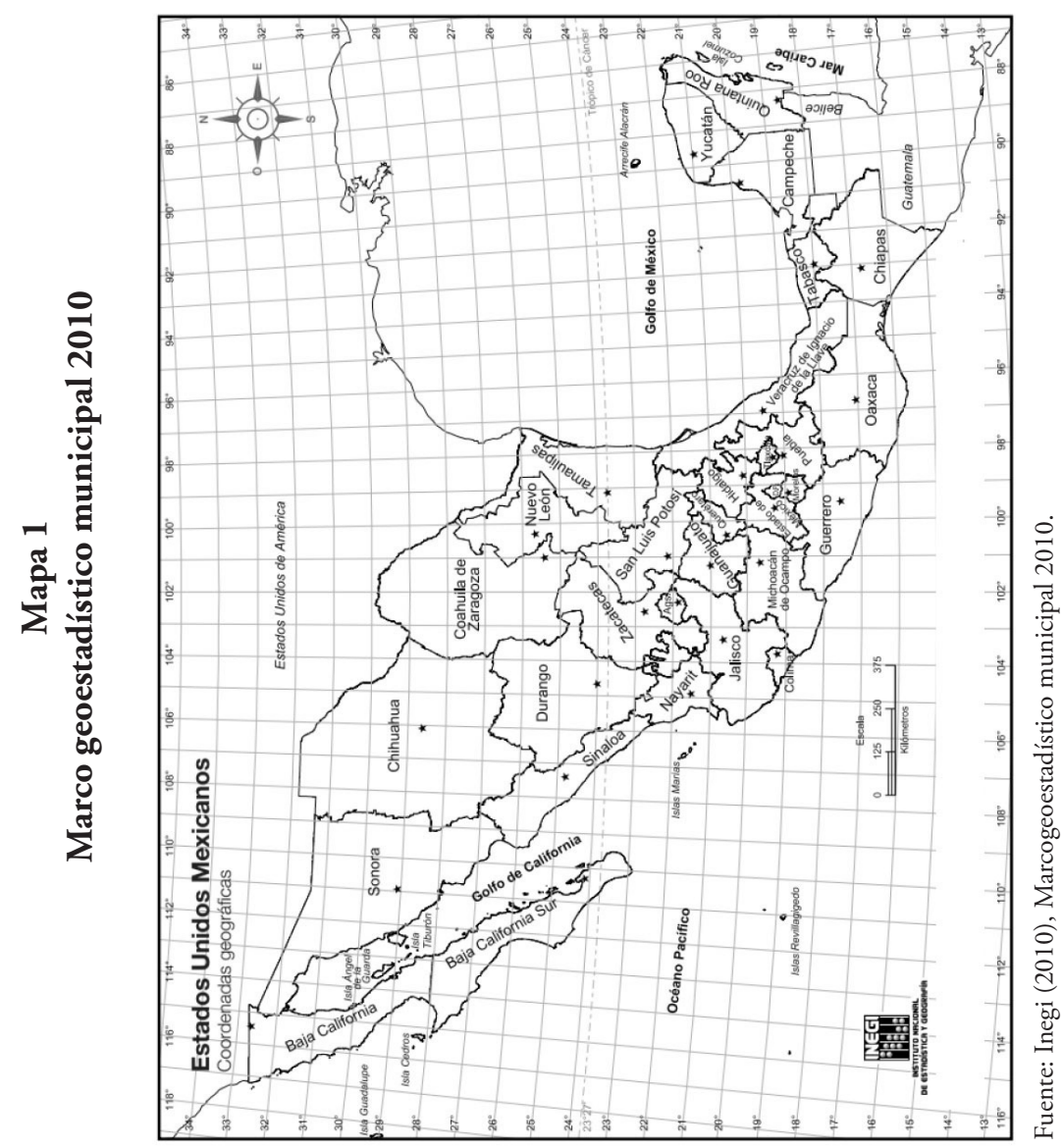




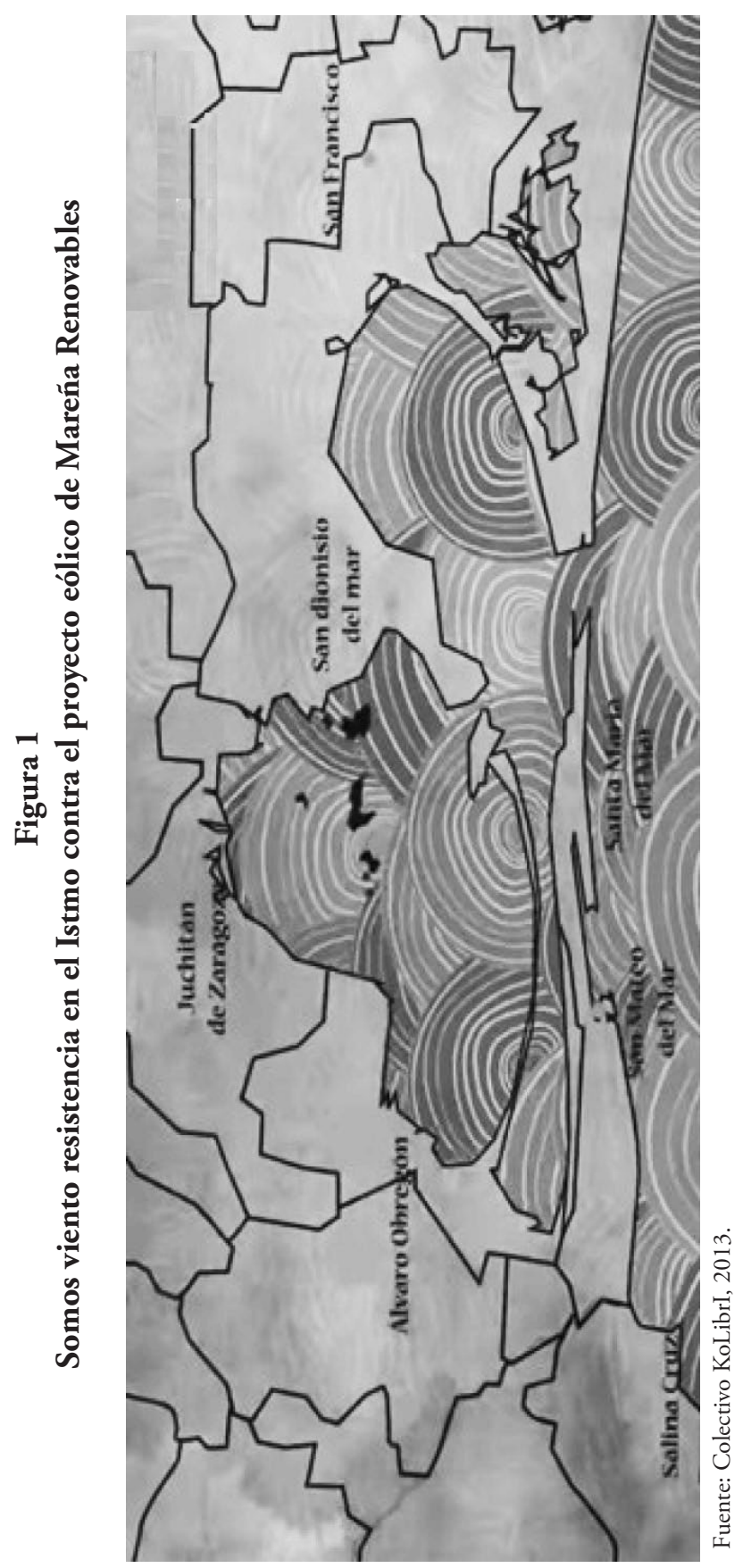


Este potencial eólico ha sido visto como una oportunidad para impulsar el desarrollo económico y social de algunas regiones, así como para contribuir moderadamente a satisfacer la demanda de electricidad en el país (Gaceta Parlamentaria, Número 3757-X, 2013). Sin embargo, el llamado Corredor Eólico del Istmo, el mayor de América Latina, ha saltado a la luz pública, no por poner en marcha las turbinas del desarrollo sino por los conflictos generados con los habitantes de la zona:

\begin{abstract}
Desde 2009 se han documentado conflictos entre las empresas eólicas y los habitantes del istmo de Tehuantepec, quienes manifiestan su inconformidad ante el abuso de las empresas, la constante es la misma: la construcción de los parques sin el permiso de los ejidatarios. [...] en julio de ese mismo ańo un grupo de 87 propietarios de 1050 hectáreas que alojan el parque eólico La Ventosa desalojaron a técnicos y operadores españoles de una subestación propiedad de la empresa española Iderranova, exigiendo que se les informara cuánta energía eléctrica genera la planta y a quién se le vende, porque afirman, a seis meses de haberse iniciado las operaciones, los dueños de las tierras sólo reciben entre 25 y 100 pesos por hectárea (Gaceta Parlamentaria, Número 3757-X, 2013).
\end{abstract}

En 2011 las confrontaciones se agudizaron:

los ejidatarios de Unión Hidalgo en el Istmo de Tehuantepec denunciaron que fueron amenazados por representantes de la empresa Demex [...]. Aseguraron que la empresa española entró a sus tierras sin proporcionarles información completa sobre el proyecto. El 21 de octubre entraron de nueva cuenta a la comunidad de Unión Hidalgo y amenazaron de muerte a las defensoras de derechos humanos, Bettina Cruz Velázquez y Maribel González, que acompańaban a los propietarios opositores al Corredor Eólico del Istmo (Gaceta Parlamentaria, Número 3757-X, 2013).

La crisis social que rodea estos proyectos es llamativa por su gran visibilidad nacional e internacional; también porque muchos de sus promotores son empresas eólicas transnacionales con la más amplia experiencia a nivel mundial; que además, son financiados por organismos internacionales y cuentan con el aval sólido del gobierno federal. Así, es sorprendente que su implementación esté amenazada por lo que parece una falta de previsión, consistente en una omisión de análisis ex ante de las diversas barreras que afectan este tipo de proyectos, desde su inserción en la planeación nacional, hasta los aspectos puntuales de su reglamentación administrativa y de su regulación económica. Como lo advierte Borja-Díaz (2003: 135).

Entre las barreras más notorias están las que tienen que ver con legislación y regulación, así como con el acceso a fuentes de financiamiento adecuado. La instauración de elementos que ayuden a superar tales barreras, ha sido un factor clave 
para el despegue de la industria eoloeléctrica en los países desarrollados [...]. Un aspecto de alta importancia es el relacionado con esquemas justos de arrendamiento.

En las siguientes secciones se analizarán aquellas barreras que, aun cuando son de las más notorias, han sido ignoradas tanto por las autoridades como por los desarrolladores y sus instituciones de financiamiento. El objetivo de este artículo es ilustrar la dinámica entre estas fallas regulatorias y la crisis social. De igual forma, se hará una reflexión, no sólo sobre el marco legal vigente, sino también sobre las perspectivas de cambio normativo en México, a raíz de la reforma energética en México de 2013.

En vista de los numerosos proyectos que existen en el Corredor Eólico de Istmo, para este trabajo se ha elegido el del Gas Natural Fenosa, el cual se ha pretendido poner en marcha, sin poder hacerlo aún. El caso de este parque eólico, llamado Bii Hioxo ("viento viejo" en zapoteco) es particularmente sugerente porque, a partir de su gestación parecen haberse potenciado los efectos de las barreras que antes amenazaban a los proyectos, sin detenerlos. Esta instalación en curso, cuyo permiso de autoabastecimiento eléctrico fue otorgado por la Comisión Reguladora de Energía (CRE) en 2008, (Resolución No. RES/372/2008) no ha corrido la misma suerte que los anteriores, puesto que las movilizaciones sociales han retrasado sustancialmente su terminación.

Lo que parecía una desavenencia negociable por cuestiones de convivencia, se ha desbordado en una serie de señalamientos que rebasan por mucho los conflictos típicos entre desarrolladores y comunidades. Como se describirá a continuación, lo que aparentemente era un conflicto derivado de una serie de arrendamientos insatisfactorios para los propietarios transmutó en un cuestionamiento del diseño de la industria eléctrica, otrora parcialmente privatizada, cuando se trata de generación que no está destinada al servicio público.

\section{La Constitución, el autoabastecimiento y el conflicto}

Antes de la reforma energética de 2013, los artículos 25 y 28 constitucionales en México establecían que la "electricidad" estaba reservada al Estado. Esta regla de exclusión había puesto en entredicho los proyectos de particulares. Si la generación de electricidad era una actividad exclusivamente pública, ¿qué hacían las empresas privadas, extranjeras y nacionales, generándola? La salida -no libre de complicaciones- parecía trazarla la misma Constitución Política de los Estados Unidos Mexicanos en su artículo 27, en el cual estipulaba que correspondía a la nación (a través 
de un organismo del Estado) la generación, transformación y distribución de energía eléctrica que estuviera destinada al servicio público. ${ }^{7}$

Luego, la modalidad de autoabastecimiento de energía eléctrica, por tener como fin el autoconsumo, al tenor de la LSPEE, no estuvo incluida dentro de las actividades consideradas como servicio público. Por lo tanto, al proveerlo únicamente para sus dueños, el parque eólico en cuestión no ha violado el precepto constitucional. Esta base incierta sostuvo la seguridad jurídica de los proyectos privados de la energía eléctrica en México.

Sin embargo, ni la legalidad ${ }^{8}$ ni la constitucionalidad del proyecto lo ha salvado de ser denostado por cómo se ha insertado en la industria eléctrica nacional, al igual que otros de su especie. De hecho, que el proyecto tenga por objeto el consumo de empresas -y por lo tanto no el servicio público- ha tenido consecuencias en la construcción de la imaginería colectiva del proyecto.

En diversos comunicados de los opositores de los parques eólicos, la figura del autoabastecimiento ha sido señalada, no sólo como un eslabón de la privatización de la industria, sino como el vehículo para la ocupación ilegítima de espacios que corresponden a la "colectividad," en todo su espectro: nación, comunidad, individuos. ${ }^{9}$

Al respecto, los cambios recientes en materia eléctrica, que dimanan de la reforma constitucional del 20 de diciembre de 2013, han llevado a cuestionar si estos permitirán o no generar soluciones a una problemática como la del Istmo de Tehuantepec. Sobre este punto cabe resaltar que, de acuerdo con la exposición de motivos de la iniciativa de reforma, los objetivos del cambio institucional son el crecimiento económico (mayor inversión en el mercado), el desarrollo incluyente (acceso universal al servicio), la transparencia y el desarrollo sustentable (Cámara de Senadores

7 Josefina Cortés explica el servicio público de esta manera: "El servicio público tiene dos elementos: objetivo y subjetivo. El elemento objetivo se define a partir de la presencia del interés general como fin a satisfacer; $y$, el elemento subjetivo, es aquel que se determina a partir de la titularidad en la propiedad, gestión y dirección de un servicio público determinado, es decir, si el servicio público se constituye a través de una persona jurídica pública, como titular exclusivo del bien o servicio, y operando como prestador directo o controlador (concesión)" (Cortés-Campos, 2007: 217).

${ }^{8}$ En un comunicado, GNF manifiesta lo siguiente: "El proyecto eólico Bií Hioxo cumple desde un inicio con toda la reglamentación exigida por las autoridades de los tres niveles de gobierno en el ámbito nacional” (Gas Natural Fenosa, 2012).

9 "Bettina Cruz, representante de la Asamblea de Pueblos Indígenas del Istmo de Tehuantepec en Defensa de la Tierra y el Territorio (APIITDTT), ha señalado que la mayoría de los proyectos eólicos, además de ser de titularidad privada, están destinados a abastecer de energía a otros emporios privados y no a la red pública y a la ciudadanía. Estos proyectos, llamados de "autoabastecimiento", se rigen bajo el principio de empresas privadas que producen energía para sí mismas o para vender a otras empresas privadas, lo cual implica un doble efecto de privatización de los recursos energéticos nacionales. Como ejemplo, sólo $22 \%$ de la energía eléctrica generada en los parques eólicos de Oaxaca es destinada a la red pública, mientras que $78 \%$ es asignado a empresas privadas como Bimbo, Walt Mart, Soriana, Cemex, Cruz Azul, Grupo FEMSA (Coca Cola, Heineken, Oxxo), etc." (Informes SiPaz, 2013). 
del Congreso de la Unión, 2013). En ese sentido, de acuerdo con el mismo documento, los resultados esperados de la reforma mencionan que el servicio eléctrico se preste en condiciones de competencia mediante el uso de energías limpias, bajo el carácter de servicio público universal.

Así, entre los objetivos planteados y los resultados que pretende el gobierno, se observa un interés por aumentar la inversión en el mercado de la producción de energía eléctrica y el aprovechamiento de recursos distintos a los hidrocarburos para la generación de electricidad. De esta forma, la reforma energética se ha centrado en la apertura del mercado y en generar condiciones, desde el marco institucional, para atraer inversionistas privados. La Constitución tan sólo presenta un objetivo general relacionado con esta problemática, consistente en que la reforma debe obedecer al "desarrollo incluyente" a través del "acceso universal al servicio".

El caso del desarrollo emprendido por Gas Natural Fenosa es muy ilustrativo de las tensiones que pueden dimanar de la introducción de grandes proyectos en terrenos donde dicha entrada es percibida, al menos por algunos, no como una oportunidad para tener mejores condiciones de vida, sino como una violación (Cámara de Senadores del Congreso de la Unión, 2013). Según sus opositores, el proyecto priva a la comunidad de sus terrenos al instalar infraestructura que no servirá para ellos, salvo por una compensación que, a su juicio, no es remotamente proporcional a los beneficios que percibirán las empresas (Comisión para el Diálogo con los Pueblos Indígenas de México, 2013). Entre los agravios señalados por ciertos miembros de la comunidad destaca la apropiación del viento, al ser aprovechado por manos extranjeras y privadas. ${ }^{10}$

\section{Lo que el viento se llevó. Las instituciones}

La literatura neoinstitucional es útil para entender el espacio en conflicto en el que se asienta el proyecto. A la luz de este marco teórico, dentro del cual elegimos usar algunos conceptos de Douglass North, es posible observar que este proyecto eólico genera expectativas en un terreno dividido entre diferentes corrientes de cambio institucional y organizacional. Según North (Chavance, 1990), la institucionalidad es entendida como un

10 "Tal como se describe en el pronunciamiento del Seminario internacional megaproyectos de energía y territorios indígenas 'El Istmo en la encrucijada', la oposición a los proyectos eólicos no tiene tanto que ver con estar en contra de la generación de energía limpia y renovable, sino en cómo se imponen los proyectos sin tener en cuenta la decisión de la población, el impacto y las afectaciones que pueden causar y el beneficio y uso que se va a hacer de la energía generada: 'no estamos en contra de la tecnología para generar energía mediante las fuentes renovables; pero sí rechazamos su uso a favor del mero lucro de las empresas y en detrimento de los pueblos y de su patrimonio biocultural'” (Informes SiPaz, 2013). 
entramado de normas formales e informales que conducen a los actores en sociedad mediante la creación de incentivos. ${ }^{11}$ Las organizaciones son igualmente relevantes, a diferencia de las instituciones, son los grupos con fines comunes insertos en este entramado institucional. $\mathrm{Al}$ respecto, Carlos Stark (2001: 3) explica lo siguiente:

Aunque coloquialmente el término “institución” se usa como sinónimo de “organización” [...] según este enfoque, las instituciones constituyen las normas formales (leyes, reglamentos, ordenanzas) y las informales (convenios, hábitos y códigos de conducta), así como los mecanismos para asegurar su cumplimiento, conformando el sistema de incentivos que guía el comportamiento de individuos y organizaciones. Las organizaciones son grupos de individuos que actúan colectivamente para lograr objetivos comunes en el marco institucional vigente.

Para los fines de este trabajo, se ha elegido la aplicación de este marco conceptual por su relevancia para explicar la fricción entre dos organizaciones que comparten un mismo espacio con normas -formales e informales- en conflicto. Hablamos de la tensa convivencia entre la empresa eólica Bií Hioxo y la Asamblea Popular del Pueblo Juchiteco (APPJ) ${ }^{12}$ dentro de un complejo entramado institucional. Claramente, se trata de dos organizaciones cuyas conductas responden de forma conflictiva por defender códigos cuyos contenidos normativos, formales e informales son, al menos en este momento, incompatibles. Entre ellas, destaca el conflicto entre la voluntad del gobierno federal de acelerar la entrada de los proyectos de infraestructura eólica que va en contrasentido con una nueva tendencia jurídica de reconocer obligaciones de consulta e inclusión comunitaria como requisitos ex ante para la implantación de éstos.

En particular, nos referimos a las obligaciones plasmadas en el Convenio 169 de la Organización Internacional del Trabajo, cuya piedra angular es la participación y consulta de las comunidades indígenas afectadas por instalaciones como éstas. ${ }^{13}$ Así que las normas formales que pretenden crear oportunidades para los inversionistas están entrando en colisión con otras normas, también formales, que respaldan la inclusión de ciertos grupos, como el APPJ, en las decisiones relacionadas con los

${ }^{11}$ Bernard Chavance (1990: 3) explica que North, al definir las instituciones como conjuntos de reglas formales e informales, señala que las que han sido culturalmente establecidas no cambiarán automáticamente al entrar en contacto con las reglas formales, lo cual causará una "tensión entre las normas formales modificadas y las normas formales".

${ }^{12}$ Para este trabajo se ha buscado algún comunicado en el que se establezca la identidad del grupo y sus objetivos, sin lograrlo. El grupo tiene un sitio en la red en el que se describen sus actividades de resistencia y sus motivos más no su identidad y composición.

${ }^{13}$ En el marco de este Convenio "la consulta previa está prevista cuando hay medidas legislativas y administrativas que puedan afectar directamente a los pueblos indígenas, o cuando se realizan actividades de exploración o explotación de recursos minerales o del subsuelo en los territorios donde habitan” (OIT Convenio 169, 1989). 
proyectos. Dado este entorno normativo, sería impreciso afirmar que mientras la empresa eólica se aferra a las normas formales para implantar su proyecto, la AAPJ se atrinchera en normas informales, por meras cuestiones culturales o ideológicas, para resistirlo. Más exacto es decir que algo del derecho los asiste a los dos y que algo de él está en su contra.

Carlos Stark, quien ha analizado las resistencias al cambio institucional en América Latina, señala el impacto que tiene la interacción entre organizaciones e instituciones, de manera atinente para este trabajo. Stark (2001: 5) advierte que: "la relación entre instituciones y organizaciones públicas en el proceso de desarrollo es compleja y bidireccional. Pueden modificarse las reglas de juego, pero ello no garantiza automáticamente la adecuación de las organizaciones públicas, cuyo cambio es normalmente más lento". En otras palabras, "lo normal es que se dé una etapa de transformaciones y conflictos, mientras la sociedad acuerda nuevas reglas del juego y se estructuran las organizaciones para jugarlo" (Stark, 2001: 16).

Más aún, el caso Bií Hioxo encuadra bien dentro del fragmento arriba citado de Stark, pues en éste se manifiestan desajustes causados, al menos en gran parte, por un conflicto entre grupos, con finalidades contradictorias, que obedecen a normas que protegen intereses al parecer incompatibles. Como se analizará, cada grupo se opone a aspectos de entramado institucional, mientras que se atrincheran en otros para defenderse. De tal suerte, Bii Hioxo se apoya en nociones de legalidad y ha exigido a las autoridades de los tres niveles de gobierno que brinden la certeza que toda inversión requiere y que, además, garanticen la "integridad física de nuestros trabajadores, los derechos de propiedad de nuestros socios propietarios de los terrenos y el normal desarrollo de nuestra inversión en la zona” (Asociación Empresarial Eólica, 2013).

En suma, Gas Natural Fenosa ha argumentado ante múltiples autoridades y medios de comunicación, su apego estricto a la legalidad al haber obtenido todos los títulos habilitantes para la realización del proyecto, tanto de índole pública como de naturaleza privada. Sin embargo, desde la trinchera de los opositores, las reglas seguidas por Bii Hioxo atentan contra sus derechos pues, no sólo se obviaron procedimientos de consulta, sino que el proyecto, por ser de autoabastecimiento eléctrico y no para la comunidad, es en sí excluyente.

Antes de la reforma energética de 2008, la inclusión de las comunidades no estaba ni siquiera como objetivo general en las reglas que rigen estos proyectos, los cuales se impulsaron como fines en sí mismos. ${ }^{14} \mathrm{En}$

\footnotetext{
${ }^{14}$ Por ejemplo, en el Programa Sectorial de Energía 2007-2012 se identificaron como objetivos sectoriales únicamente los siguientes: "Objetivo II.1.: Fomentar niveles tarifarios que permitan cubrir costos relacionados con una operación eficiente de los organismos públicos del sector eléctrico. Objetivo II.2.: Equilibrar el portafolio de fuentes primarias de energía. Objetivo II.3.: Fortalecer a los organismos públicos del sector eléctrico en lo referente a prácticas operativas y estándares tanto
} 
todo caso, se han promovido por objetivos de sustentabilidad ambiental, que no social (Diario Oficial de la Federación, 2008). Especialmente desde las reformas normativas de 2008 que dieron cabida a un régimen particular de las energías renovables, se ha manifestado con más claridad la voluntad oficial, socialmente irreflexiva, de incorporar tecnologías limpias (Cámara de Diputados del H. Congreso de la Unión, 2008). Para ello, se ha agilizado la expedición de los títulos habilitantes para la implantación de los mismos. ${ }^{15}$ Sin embargo, éstos se han instalado en zonas donde su recepción dista de ser neutral. Es posible que la laxitud con la que se han otorgado los permisos y autorizaciones haya creado una falsa expectativa en los inversionistas de que su introducción en el ámbito estatal y municipal sería igualmente fluida (Centro de Estudios Espinosa Yglesias, 2010).

Por esta razón, las puertas que abre el gobierno federal para las energías renovables, en la práctica, las llevan por un sendero incierto. Ni el discurso centralizado de los órganos de decisión federales ni las reglas del juego que ellos emiten han podido pasar de largo las barreras que podrían surgir en los estados y municipios. En una entrevista con funcionarios de la Subsecretaría de Electricidad, de la Secretaría de Energía, comentaron que, en el caso específico de Bii Hioxo, sus representantes se han dolido de no haber sido advertidos sobre los escollos a nivel estatal y municipal. Aquí la pregunta sería si este reclamo es razonable. ¿No le corresponde al inversionista hacer un mapeo de riesgos, de todos los tipos, antes de tocar puertas y cruzarlas? (Deloitte Youche Tohmatsu Limited, 2009). Es difícil determinar si los dueños de Bií Hioxo llevaron a cabo todos esos deberes de cuidado exigidos internacionalmente a los inversionistas, cuando reclaman dańos patrimoniales a un Estado, lo cierto es que las fallas en la regulación son un agravante a lo que parece una falta de cuidado.

\section{Barreras regulatorias. ¿Qué le cierra el paso al viento?}

Como se advirtió en la parte introductoria de este trabajo, los estudios que se abocan al análisis del conflicto han puesto el acento en las cuestio-

de calidad como de confiabilidad en los servicios que ofrecen. Objetivo III.1.: Promover el uso y producción eficientes de la energía. Objetivo III.2.: Fomentar el aprovechamiento de fuentes renovables de energía y biocombustibles técnica, económica, ambiental y socialmente viables. Objetivo IV.1.: Mitigar el incremento en las emisiones de Gases Efecto Invernadero (GEI)" (Diario Oficial de la Federación, 2008). Nótese que, entre los objetivos del Programa, no figura la electrificación a las comunidades rurales.

${ }^{15}$ Es por eso que el Programa Sectorial de Energía de 2001-2006 enfatizó la necesidad de coordinar los esfuerzos de las distintas autoridades involucradas en el ámbito energético -SENER, CRE, CFE y LFC- para dar agilidad a los procesos de otorgamiento de las licencias y permisos que se requieren y, de este modo, facilitar el desarrollo de los proyectos tendentes a impulsar el uso de energías limpias (Diario Oficial de la Federación, 2002). 
nes derivadas de los contratos de arrendamiento. Sin embargo, documentos obtenidos de GNF revelan que la inconformidad en la contraprestación por el uso de la tierra no es una cuestión única, aunque sea sobresaliente. ${ }^{16}$ En efecto, en un estudio realizado por el Centro de Investigaciones y Estudios Superiores en Antropología Social (CIESAS) sobre el impacto de este tipo de proyectos en el Istmo, el desajuste principal se atribuye a la "incursión local de la internalización del mercado la cual, para las comunidades oaxaqueñas, representa un riesgo de fragmentación ${ }^{17}$ interna de las comunidades en función del proceso acelerado de globalización, multiculturalismo e impactos económicos de gran escala" (NahmadSitton, 2011: 1).

La falta de una ponderación en cuanto a la afectación comunitaria que podría representar un proyecto de autoabastecimiento eléctrico se puede

\footnotetext{
${ }^{16}$ Nos referimos al estudio de percepción emitido por GNF en 2010 en el que concluye que: "A pesar de que existen grupos opositores al proyecto bien identificados, no se registra un rechazo claro al proyecto, pero tampoco un apoyo contundente a la creación del Parque Eólico; lo que representa un área de oportunidad para posicionarlo en la opinión pública”. (El énfasis es de GNF, documento inédito). Es importante resaltar que la conclusión fue producto de una encuesta realizada a los pobladores rurales por parte de GNF. Las preguntas que resulta importante destacar son las siguientes: "Como habitante de Juchitán, ¿qué tanto le preocupa la construcción de este parque eólico?", 40\% respondió "me preocupa mucho" o "me preocupa" y 36\% se mostró neutral o con poca preocupación. En el primer grupo, se puntualizaron preocupaciones como pérdida de cosechas; la generación de empleos únicamente es durante la fase de construcción; el beneficio es para aquellos que rentan sus tierras; puede provocar la desintegración del pueblo de Juchitán; afectación a la fauna (por ejemplo, en el caso de comunidades de pescadores), entre otras. Por otro lado, la siguiente pregunta es fundamental para entender la problemática social y establece: "¿Si un parque eólico tuviera todos los beneficios que le acabo de mencionar usted lo apoyaría?". Entre los beneficios se encuentran los siguientes: genera más empleos; no contamina puesto que es ecológico; sería una fuente de ingreso; una fuente alterna de energía; mientras sólo sea una; si lo ponen donde no estorbe; la energía sería menos cara. En este sentido $88 \%$ de los encuestados respondió "sí". Empero, estos beneficios son meramente artificiales. En primer lugar, en lo que se refiere al empleo, el tiempo de construcción para un proyecto eoloeléctrico grande generalmente es de un año o menos. En esta etapa la mayoría de la población común resulta favorecida, pero una vez concluida ésta e iniciada la etapa de operación, el empleo generado es insuficiente para las demandas de la población. En segundo lugar, no se trata de un único proyecto, sino de 16 parques que incluyen aproximadamente 132 aerogeneradores. En tercer lugar, como anteriormente se expuso, la energía no es "más barata" puesto que las desarrolladoras no están en posibilidad de vender los excedentes de energía generada a la población. Finalmente, a pesar de que las empresas con instalaciones eoloeléctricas en el Corredor del Istmo sí tienen proyectos sociales para mitigar los impactos negativos que implica la operación de las mismas, estos proyectos son de bajo impacto para el total de la comunidad, pues quedan reducidos a algunas obras de infraestructura como la pavimentación de calles, bardas o techos en escuelas y algunos talleres. No hay un impacto sustancialmente benéfico, ya que no existen hoy proyectos de carácter productivo que impulsen la integración comunitaria y su desarrollo (Sánchez-Camacho, 2007: 218-219).

${ }^{17}$ Se explica así la fragmentación que ya existe en el Istmo: "La confrontación entre los pueblos que están de acuerdo en arrendar sus terrenos contra las que oponen resistencia ha crecido sin que el gobierno medie de manera eficaz. El conflicto entre las comunidades de San Mateo del Mar, San Dionisio del Mar, Santa María del Mar, Unión Hidalgo y Santa María Xadani ha dejado heridos, una persona muerta y bloqueos de caminos que los comunican y proveen de servicios, para presionarse entre ellos ya sea para arrendar sus tierras o rescindir contratos. El resultado es obvio: las comunidades se dividen y las trasnacionales se instalan” (Zavala, 2012).
} 
notar desde los instrumentos de planeación de este sector. De hecho, el primero $^{18}$ en mencionar la incorporación de energías renovables en México no manifiesta como objetivo un beneficio claro y directo para las comunidades en las que se insertan, debido a que este tipo de inversiones no ha estado proyectado para desempeñar un papel importante en prestación del servicio público de energía eléctrica, sino por inversionistas privados, para otros fines.

Así, la incorporación de energías renovables ha dependido de la participación de particulares, sus beneficios han sido expresados de forma genérica, ${ }^{19}$ cuidando de no hacer alusión alguna al servicio público que ha estado reservado al Estado. Por esta razón, el primer instrumento de planeación que se refiere a esta clase de infraestructura es más bien cauteloso de no mencionar que, gracias a ella, las comunidades tendrán una mayor cobertura eléctrica, ${ }^{20}$ mediante "la creación de un marco regulatorio para la concentración y participación de los sectores público y privado en el ámbito de energías renovables" (Diario Oficial de la Federación, 2002). En suma, los objetivos mencionados en este instrumento de planeación indican una serie de objetivos distantes de las necesidades inmediatas de los habitantes de las zonas donde se instalan los proyectos (Diario Oficial de la Federación, 2002).

Es importante destacar que en aquel momento no había una ley específica, como la ya referida ley de 2008, para el desarrollo de proyectos de generación a partir del uso de energías renovables. Existía entonces un régimen indiferenciado para todos los proyectos privados, ya fueran de energías renovables o de otras fuentes. De tal suerte, la única base normativa que sostenía estos proyectos innovadores, con todas sus particularidades técnicas y económicas, eran una ley y un reglamento cuyo centro ha sido un monopolio eléctrico mayormente usuario de combustibles fósiles.

${ }^{18}$ Se trata del Programa Sectorial de Energía 2001-2006 (Diario Oficial de la Federación, 2002).

${ }^{19}$ Se resalta que, entre los proyectos a los que se pretende dar impulso, destaca el de autoabastecimiento de energía eléctrica y térmica, particularmente en el sector industrial. En este sentido, el plan sí esboza un argumento a favor de los beneficios sociales de estas instalaciones pues, al poder evitar las tarifas más caras del servicio público, las empresas crean un entorno de mayor competitividad en la producción, lo cual se traduce en un beneficio social. Sin brindar datos de soporte, se presupone que el solo hecho de que las propias empresas generen la electricidad que demandan conlleva a un significativo número de beneficios, tanto para el sector energético como para la sociedad en su conjunto (Diario Oficial de la Federación, 2002).

${ }^{20}$ Textualmente, el Programa Sectorial dice así: "Ello constituye la posibilidad de un mejor desarrollo de las energías renovables y representa una gran oportunidad para una mayor diversificación energética, reducir la dependencia del petróleo, ampliar la base industrial en un área que puede tener valor estratégico en el futuro y atenuar los impactos ambientales consecuencia de la producción, distribución y uso finales de las formas de energía convencionales" (Diario Oficial de la Federación, 2002). 
Hasta la emisión de la Ley para el Aprovechamiento de Energías Renovables y el Financiamiento de la Transición Energética (LAERFTE), en 2008, se estipuló que las figuras de generación privadas usaran hidrocarburos u otras energías tenían cabida únicamente dentro de la LSPEE, bajo la modalidad de "no servicio público". Y dentro de este espacio estrecho, en el que los particulares podrían generar para fines acotados, había un resquicio aún más restringido para la generación eléctrica con energías renovables. Sobre este punto, Sergio Oceransky relata una entrevista con un alto funcionario público respecto del estado de la cuestión justo antes de que se discutiera y promulgara la primera ley específica que diera sustento jurídico a las energías renovables en México: "Antonio Pérez Rodríguez, entonces director de Energía y Medio Ambiente de la Secretaría de Energía, explica que las fuentes renovables de energía se insertaron en la política pública mexicana con el objetivo principal de diversificar las fuentes de energía, que no para cumplimiento de fines ambientales o sociales" (Oceransky, 2009: 16).

Por querer pasar de largo estos riesgos y seguir adelante con el proyecto, el gobierno federal ha otorgado más permisos sin crear un andamiaje jurídico robusto ante posibles conflictos sociales. ${ }^{21}$ Así, los primeros permisionarios privados de energía eólica se aventuraron en un territorio donde la holgura del marco jurídico, en lugar de facilitar la entrada de los proyectos, en algunos casos, llegaron a complicarla. En comparación con la entrevista que Oceransky hizo hace tiempo, llama la atención que durante la ya mencionada conversación con funcionarios de la Subsecretaría de Electricidad, éstos hayan relatado que los permisionarios de estos proyectos, hoy agraviados por conflictos sociales, manifiestan haber llegado a Oaxaca en el desamparo jurídico a pesar de tener todos sus papeles en "regla". 22

Esta afirmación, que en principio suena más a un descargo de responsabilidad por parte de los desarrolladores, tiene eco en un estudio del

21 "El Secretario de Energía, Jordy Herrera, anunció el mes pasado que se otorgaron 18 nuevos permisos para la creación de parques de energía eólica en la zona del Istmo de Tehuantepec y que el gobierno federal negocia con inversionistas privados incentivos que impulsen la construcción de nuevos parques en la región" (Zavala, 2012).

${ }^{22}$ Parece insólito que habiendo mecanismos institucionales, por débiles que se presenten, ni las empresas internacionales ni las nacionales, se preocupen por darles seguimiento. Incluso, independientemente, de que las desarrolladoras aleguen tener sus papeles "en regla" -haciendo caso omiso a las demandas sociales- no es el primer parque eólico construido en el mundo. Por ejemplo, en España, al igual que en México las energías renovables comienzan a tener un papel relevante en el desarrollo y economía del país. En este sentido, la Región de Murcia se presenta como una especie de "ideal" por representar los posibles beneficios que puede conllevar el hecho de realizar de manera ex ante un estudio no sólo de impacto ambiental, sino social, por medio de la opinión que los ciudadanos de la Región tienen de la implementación y uso de las energías renovables (Molina-Ruiz y Tudela-Serrano, 2006). 
impacto social de los proyectos eólicos en la zona del Istmo, que dice lo siguiente:

Carentes de una legislación lo suficientemente clara, y con la poca o nula orientación gubernamental, las empresas se acercaron de forma directa con los propietarios de las tierras que les interesaba rentar, iniciando así un proceso complejo, no sólo por la falta de experiencia para la negociación por parte de los terratenientes, sino por la falta de condiciones estipuladas para los desarrolladores. Esta situación ha generado desconfianza y multitud de casos registrados como abuso ya que las comunidades no estaban habituadas a negociar con la iniciativa privada, y esperaban un trato similar al de los programas de gobierno (NahmadSitton, 2011: 108).

Tal era la situación de los proyectos eólicos antes de la promulgación de la primera ley específica para el fomento de las energías renovables, en México esta inserción se dio en el curso de una reforma, cuyo objeto principal de reflexión era la industria de los hidrocarburos, en 2008. Así, la primera legislación para la promoción de las energías renovables y para la transición energética se gestó en una época en la que los partidos políticos se arrebatan las visiones "verdes y vanguardistas" del sector y en la que partidos opositores y expertos clamaron la estrechez de criterio de las reformas propuestas. ${ }^{23}$

\section{La consulta pública: ¿deber jurídico o simulación?}

No cabe en este trabajo detenerse a revisar las circunstancias puntuales de la discusión y promulgación de la legislación. Lo que en todo caso debe subrayarse es que el artículo 21 de la LAERFTE, sí contiene una obligación de consulta pública. Sobre ello, la doctora Josefina Cortés explica:

La Ley dispone que en todo proyecto de generación de electricidad con una capacidad mayor a los 2.5 MW, y previo a la autorización de cambio de uso de suelo, se deberá asegurar la participación de las comunidades locales y regionales, de los grupos potencialmente afectados y de los grupos e individuos interesados en el seguimiento de los proyectos (Art. 21). Tales estrategias responden al objetivo de conciliar el desarrollo rural sustentable, la protección del medio ambiente y los derechos agrarios (Cortés-Campos, s/f: 25).

Por otra parte, aun cuando existe esta obligación de consulta pública establecida en el dispositivo antes citado de la LAERFTE, esta última no dicta los pasos, ni siquiera los criterios generales que deben seguirse para que se haga efectiva. Más aún, el reglamento, donde podrían detallarse más los procedimientos mínimos de consulta, guarda incluso

${ }^{23}$ Para un resumen de estas críticas y argumentos, véase (Rojas, 2014). 
mayor silencio. Visiblemente, al momento de reglamentar, no había voluntad en el Ejecutivo de hacer valer estas obligaciones mediante procedimientos definidos de consulta a los cuales no habían estado sujetos los permisionarios en México, al menos por las leyes nacionales (Oceransky, 2009: 8). ${ }^{24}$

Sin embargo, con obligación legal o sin ella, algunos empresarios argumentan que siempre se contó con la anuencia comunitaria. Por ejemplo, Eduardo Zenteno, anterior presidente de la Asociación Mexicana de Energía Eólica (AMDEE, 2010 y 2012) ha manifestado que, aun a falta procedimientos de consulta establecidos en la LSPEE, y a pesar de los escasamente reglados en la LAERFTE, la aprobación comunitaria ha estado suficientemente manifestada en los numerosos contratos de arrendamiento que se tienen celebrados con los propietarios. Sobre ello, relata Oceransky (2009: 16):

\begin{abstract}
Eduardo Zenteno, Presidente la de AMDEE, ha manifestado que la mayoría de las comunidades están a favor de los proyectos y sustenta esta afirmación en los 1500 contratos celebrados. Él afirma que cada empresa informa a los agricultores con los que contrata y que existe el diálogo con los propietarios legítimos. Sin embargo, cuando se le pregunta si se ha reunido con las comunidades, él responde que no es necesario pues es suficiente tratar con los 10 líderes de la región, quienes advirtieron a los opositores de los proyectos de los riesgos de causar desorden pues Oaxaca es una región violenta. Esta respuesta es indicio de que se emplearon prácticas caciquistas para poner en marcha los proyectos eólicos en Oaxaca.
\end{abstract}

Es riesgoso aventurar conclusiones sobre el grado de representatividad que pudieran haber tenido los líderes frente a los individuos de las comunidades y llegar a ellas no es el propósito de este trabajo. Empero, sí parece problemático suponer que el solo hecho de que se hayan firmado 1500 contratos implica el consentimiento a todo el proyecto, por mediar una representación sustantiva de los miembros de la comunidad. En este sentido, las afirmaciones de Zenteno revelan que los desarrolladores, en el mejor de los casos, sobrevaloraron el significado y las implicaciones de la firma de los contratos. La aceptación de dar el uso temporal de los terrenos mediante arrendamiento no debe ser interpretada tan extensivamente como para suponer el consentimiento integral a los parques, con todas sus implicaciones sociales y ambientales, lo cual es especialmente

${ }^{24}$ Oceransky explica que, tanto Zenteno como otros miembros de la AMDEE, son muy críticos de la ley y afirman que no debe ser aprobada tal como existía al principio ya que dice que los recursos renovables son de interés nacional lo cual podría limitar la participación privada e incluso contienen el pago de una contraprestación al Estado por el uso del viento. También establece la creación de un comité consultivo para cada proyecto, con el derecho de vetarlo, compuesto en lo principal por representantes municipales y comunitarios. A su juicio, la creación de esos comités sólo fomentará la corrupción y la burocracia. 
relevante si se consideran los problemas de transparencia detectados en la interacción entre los desarrolladores y las comunidades afectadas. En el estudio de impacto social ya citado, se observa que:

en el proceso de acercamiento y convencimiento de los ejidatarios, los desarrolladores llevan información a reuniones en las que explican con lenguaje técnico el funcionamiento del parque, esto referido por los entrevistados en las diferentes comunidades, pero el proceso comunicativo no es asertivo, lo que genera dudas. También omite dar información sobre la venta y distribución de la energía, asi como de las consecuencias que pudiera generar, dejando ahi una grieta que es aprovechada por los grupos opositores (Nahmad-Sitton, 2011: 12).

El último punto, resaltado en cursivas, es de especial interés pues se refiere a la disociación de estos proyectos con respecto al de beneficio social. Sobre ello, volvemos a la entrevista ya citada de Oceransky (2009) con Antonio Pérez Rodríguez, otrora director de Energía y Medio Ambiente de la Secretaría de Energía, en la cual revela que, al menos al momento en que se hizo la entrevista, "no se contemplaban mayores beneficios sociales para las comunidades derivados de los proyectos". De hecho, Pérez Rodríguez señaló que hasta hace algunos pocos años, ${ }^{25}$ no habia "leyes que garantizaran a las comunidades otro beneficio que los ingresos derivados de los contratos arrendamiento, celebrados entre las empresas y las comunidades". Así, pues, se destaca que estos proyectos fueron ideados para incentivar la inversión en renovables, pero no para que la energía generada llegara a beneficiar a las poblaciones locales.

Y si las comunidades se quejan de que la luz no les llega, las empresas se duelen de que generarla les sale caro, contra las finalidades más elementales del autoabastecimiento. Por esta razón, una de las mayores prioridades de las empresas ha sido minimizar costos, pues argumentan que el modelo regulatorio en vigor en México hace de los proyectos eólicos en este país de los más costosos en el mundo.

Oscar Galindo Ríos, también entrevistado por Oceransky, argumentó que es importante tomar en cuenta las circunstancias en las que los proyectos han surgido. Aquellos puestos en marcha al momento de la entrevista habían pagado un precio muy alto por la construcción de la infraestructura de transmisión, ${ }^{26}$ un precio en aumento por las turbinas, además de que no había, ni existe aún, una tarifa incentivada (feed in tariff) para garantizar su viabilidad económica.

Más aún, recalcó que, al no ser muy rentables, la conclusión de algunos es incierta; que en el caso de Oaxaca se trata de operaciones sobre

\footnotetext{
${ }^{25}$ Esto es, antes de la promulgación de la LAPFRE.

${ }^{26}$ Ya no es el caso pues desde hace algunos ańos, existe una tarifa de porteo (transmisión) altamente subsidiada.
} 
terrenos cuya actividad sísmica es elevada, con poca infraestructura y con escasa certeza sobre los derechos de propiedad de los terrenos. Por todas estas razones, los parques eólicos en Oaxaca son extraordinariamente costosos. Ante estas vicisitudes, los desarrolladores argumentan que han pagado un precio justo por los arrendamientos; que han seguido parámetros internacionales de mercado para la obtención del uso de los terrenos. ${ }^{27}$

El tema de la consulta pública debía ser abordado de manera viable en las leyes secundarias en materia eléctrica. El caso de Bií Hioxo, cuyo análisis se atenderá en la sección siguiente, prendió una señal de alarma de que el deber de consulta tendría que ser analizado con mayor profundidad, para consignarse en la nueva regulación del sector eléctrico.

\section{Bií Hioxo. Viento viejo, nuevas revueltas}

Tras haber analizado el complejo tejido institucional que sostiene la generación eólica en Oaxaca, pasemos a un análisis breve de la crisis del proyecto de Gas Natural Fenosa, Bii Hioxo, cuya historia es el epítome de todas las fallas regulatorias ya mencionadas. La crisis de este proyecto es especialmente interesante por las razones siguientes: primero, con respecto a Gas Natural Fenosa, la titular del permiso Bií Hioxo es una empresa con amplia trayectoria en México y titular de varios permisos de distribución de gas natural en distintas partes de la república, así que su experiencia con autoridades de todos los niveles de gobierno debe estar fuera de duda.

En segundo término, aun cuando su permiso fue otorgado en 2008, y la terminación de las obras y su entrada en operaciones se calculaba para 2012, a la fecha en que se escribe este artículo, la construcción se ha retrasado a causa de los bloqueos y disturbios de diversos grupos, con el protagonismo de la ya mencionada APPJ; en tercer lugar, la exacerbación de los disturbios, que iniciaron en febrero de 2013 (Gas Natural Fenosa, 2013), coincide con la emisión de dos sentencias judiciales que sientan antecedentes importantes para la implantación de infraestructura de cualquier índole. Se trata de las sentencias que conciernen a la construc-

\footnotetext{
${ }^{27}$ Dice el estudio coordinado por Nahmad: "Los pagos por arrendamiento basados en regalías en la región del Istmo dependerán en gran medida del precio al cual la central pueda vender la energía, puesto que los factores de planta previstos tenderán a ser bastante predecibles en diferentes sitios. Se examinaron varios escenarios, los cuales generaron varios pagos proyectados en un rango desde $\$ 180 /$ Ha hasta más de $\$ 1000$ por hectárea. Por ejemplo, asumiendo precios de venta de la energía entre $\$ 0.035$ y $\$ 0.08 / \mathrm{kWh}$, un factor de planta de $40 \%$ y un acuerdo de arrendamiento por regalías de $2 \%$ de los ingresos brutos, los pagos proyectados por MW quedarían en un rango entre $\$ 2,453$ y $\$ 5,606$, lo cual reflejaría un rango por hectárea entre aproximadamente US $\$ 320 / \mathrm{Ha}$ y \$728/Ha” (Nahmad-Sitton, 2011: 41).
} 
ción del Acueducto Independencia (A.R. 631/2012) y de la suspensión de las concesiones mineras en la zona de Wirikuta. ${ }^{28}$

Sin pretender entrar en un análisis detallado de estas sentencias, lo cual sería materia de otro trabajo, cabe señalar que se trata de resoluciones emitidas por el Poder Judicial de la federación en las que se valida la obligación de consulta pública y se establecen lineamientos para hacerla efectiva. Más aún, en entrevista con funcionarios de la Subsecretaría de Electricidad, reconocieron que la emisión de estas sentencias le ha puesto a "dientes" a la ya mencionada obligación de consulta pública establecida en el artículo 21 de la LAERFTE.

Ante este escenario, los funcionarios de esta Subsecretaría se manifestaron conscientes de que debían emitirse lineamientos para que esta consulta sea efectiva, pero que también han de tomarse providencias para que la implantación de proyectos de generación privada sigan adelante. La inclusión de las comunidades no debe implicar la parálisis de estos proyectos eléctricos. En suma, ellos manifestaron que ha llegado el momento de poner en orden el marco institucional de las energías renovables para reducir, tanto como sea posible, la fricción entre las organizaciones imbricadas en él.

Este reto, cuyo fondo es la validación social de los proyectos, no será menor si se toma en cuenta la distancia que guardan sus beneficios de las comunidades. ¿Cómo explicarles con claridad a las comunidades que se va a utilizar sus terrenos para electrificar empresas en tierras lejanas? ¿Cómo justificar la instalación y presencia de aerogeneradores gigantes con ventajas que, para un poblador rural, bien podrían parecer meras abstracciones? ¿Competitividad? ¿Diversificación energética? ¿Desarrollo tecnológico? ¿Disminución de gases efecto invernadero? El reto no es menor si se tiene en cuenta que las reglas del juego y sus objetivos son dispares y contrastantes para los jugadores. Retomando lo expresado por Stark, y su aplicación del marco neoinstitucional a este caso, cada organización en esta historia responde a un juego de reglas para defender intereses en conflicto.

La crisis que aqueja este proyecto lleva ya varios meses y no vale la pena detenerse en la anécdota. Por lo tanto, se hará tan sólo un recuento muy somero de los hechos más relevantes para fines de encuadrarlos en su contexto. Según información obtenida de la prensa y de Gas Natural Fenosa, el conflicto estalló en febrero de 2013 cuando la empresa se disponía a iniciar las obras, una vez obtenidos los permisos y contratos necesarios. Estas fuentes revelan que, al percatarse de la presencia de maquinarias y movimientos para arrancar los trabajos de construcción,

\footnotetext{
28 "Un juez federal de distrito decretó la suspensión provisional de las concesiones a las mineras canadienses que pretenden explotar el territorio sagrado de Wirikuta, en San Luis Potosí, con lo que el pueblo wixárika logró una victoria jurídica parcial" (El Economista, 2013).
} 
campesinos y pescadores, ya agrupados como APPJ, bloquearon el acceso al flanco sur del polígono donde se ha pretendido instalar la infraestructura. Según los pobladores, el inicio de las protestas se debió al temor de que las obras y el proyecto afectarían sustancialmente su calidad de vida al impedirles el acceso a sus tierras y lagunas. ${ }^{29}$

También alegaron la ilegalidad de la adquisición de terrenos de una extensión de 1500 hectáreas, ya que por tratarse de tierras comunales, ellos requieren procedimientos de ley distintos al simple arrendamiento. De ahí en adelante, los enfrentamientos han continuado, algunos con manifestaciones violentas, como el enfrentamiento a tiros entre policías y "supuestos miembros" de la APPJ. Desde entonces, el conflicto ha subido de tono en la medida en que se han involucrado un mayor número de grupos, incluyendo organizaciones no gubernamentales, nacionales y extranjeras. Incluso, se organizó un seminario internacional "antieólico", con resonancias en el continente europeo.

La colisión ha sido particularmente difícil porque los dos grupos principalmente involucrados, desde sus ángulos respectivos, piden lo mismo: la aplicación de la ley. El reclamo de legalidad de GNF se sustenta en diversos títulos administrativos, en instrumentos privados $y$, en particular, en los contratos de arrendamiento sobre los cuales se argumenta que son jurídicamente robustos. A los opositores también los asisten argumentos de legalidad consistentes en la existencia del derecho a la consulta previa, establecido en el artículo 21 de la LAERFTE y en el Convenio 169 de la OIT, ahora avalado por dos sentencias del Poder Judicial. Así, de haber sido consultados con anterioridad, habrían al menos cuestionado un proyecto en el que los beneficios a la comunidad no son su objetivo primordial.

Sobre esto último, cabe mencionar que, en una conversación privada con un funcionario de GNF, expresó que tal vez el único y más grave error de su empresa fue seguir la misma estrategia de otras que la precedieron en el Istmo; esto es, continuar el mismo patrón de exclusión marcado por los instrumentos de planeación de la LSPEE, e incluso ignorar la tenue señal de consulta pública a la que obliga la LAERFTE en su citado artículo 21. Si este funcionario tiene razón, entonces la noción de legalidad que han seguido los proyectos ha sido asaz estrecha; y dentro de esa misma noción, en la que no había cabida para la voluntad de los pobla-

${ }^{29} \mathrm{Y}$ debido que para ellos estos dos ámbitos son fuente de vida, los pobladores retoman argumentos ambientalistas para manifestar su inconformidad. En este sentido, sostienen que si bien los parques eólicos presentan un impacto ambiental relativamente pequeño, en comparación con otras fuentes de energía convencionales, también son generadores de ruido excesivo, impacto visual negativo, muerte de aves endémicas por colisión con las palas (esto en virtud de que el Istmo de Tehuantepec está ubicado en el corredor de migración de aves) y disminución de la fauna sobre la que se asientan los aerogeneradores (Molina-Ruiz yTudela-Serrano, 2008). 
dores, se creó inconformidad, luego irritación y al final fuerte resistencia contra el proyecto.

A juicio de este funcionario, GNF hoy vive las consecuencias de un marco de regulación que ha excluido a las comunidades, no sólo de mecanismos eficaces de consulta pública, sino también de los beneficios directos del aprovechamiento de la energía eléctrica. Así que la desorientación de la empresa, sobre lo que podría sobrevenir fue, en parte, por las fallas regulatorias, pero también su falta de previsión sobre sus consecuencias.

\section{Corrientes de cambio. La iniciativa de reforma eléctrica y su aprobación}

$\mathrm{Al}$ momento de elaborar este trabajo, surgió una pieza más en el tablero: el paquete de iniciativas de leyes secundarias en materia energética y su aprobación en agosto de 2013. El texto de las iniciativas legales demuestra con mayor claridad el entendimiento que el gobierno federal tiene de las cuestiones sociales involucradas en la apertura del mercado energético. Un primer punto a considerar es la inclusión en la Ley de Industria Eléctrica de un capítulo sobre el impacto social y el desarrollo sustentable. La ley se limita a tan sólo tres artículos en todo el proyecto en los que se enuncian los principios de sustentabilidad y de respeto a los derechos humanos de las comunidades y pueblos indígenas de las regiones en las que se pretenda desarrollar algún proyecto de la industria (Ley de la Industria Eléctrica, 2014, arts. 117-120).

Más aún, la ley reconoce la obligación de la Secretaría de Energía de desarrollar consultas necesarias y cualquier otra actividad para salvaguardar los principios antes enunciados. Sin embargo, en la misma no se establece el carácter vinculante de los resultados de la consulta pública en una determinada región, así como tampoco se establece un proceso claro para la implementación de estos mecanismos.

En realidad, la propuesta plantea un margen discrecional muy amplio para que el Ejecutivo decida cómo desarrollar la consulta y definir sus efectos sobre los proyectos en la industria eléctrica. Por otro lado, resulta cuestionable que las secretarías de Energía, Economía y Gobernación sean las dependencias competentes para conocer de las cuestiones de sustentabilidad y respeto a los derechos humanos, tan sólo por su experiencia en los aspectos técnicos y económicos involucrados en la industria. Sin duda, tendrían que conocer de estos temas otras dependencias, como la Secretaría de Desarrollo y la Secretaría del Medio Ambiente, debido a su experiencia institucional respecto del impacto social y ambiental que producen estos megaproyectos de inversión. 
Además, aun cuando ya existe una nueva Ley de la Industria Eléctrica, que se supone resolvería estos conflictos, aún no queda claro cómo este terreno ampliado de participación de las empresas será compatible con generar mejores condiciones de vida para las comunidades y se alineará con sus derechos. La reforma constitucional y la ley únicamente permiten la existencia de un mercado de generación mayorista en el que sólo los grandes usuarios, llamados "usuarios calificados," podrán consumir la energía generada por los generadores privados. Al igual que antes, los generadores privados podrán argumentar que no pueden prestar el servicio directamente a los que menos tienen porque la Constitución no se lo permite. Es una justificación soñada para quienes persiguen, por su naturaleza de emprendimiento comercial, el lucro sobre todos los demás objetivos.

De igual forma, otra cuestión en esta ley sobre la Industria Eléctrica que guarda especial conexión con los mecanismos de consulta es la referente al uso y ocupación de los terrenos para los proyectos del sector. Debe mencionarse que esta ley establece el carácter de "utilidad pública", respecto de la ocupación o afectación superficial de inmuebles, para el desarrollo de las actividades de la industria eléctrica. Esta situación especial de utilidad pública, ya establecida en la ley, significa que los terrenos, sean de quiénes sean, deberán abrirse a un proceso de negociación para ser objeto de la llamada "ocupación superficial" por parte de los desarrolladores.

Esta ley al parecer pretende proteger los intereses de los propietarios y ocupantes mediante la formalización por escrito de las ofertas por los terrenos, la inclusión de testigos sociales durante la celebración de las negociaciones sobre los mismos, una obligación de pago "proporcional" al uso de éstos, y al proporcionar la asesoría de la Procuraduría Agraria a los ocupantes de terrenos ejidales o comunales (Ley de la Industria Eléctrica, 2014, arts. 71-76).

Sin embargo, la calificación de utilidad pública que esta ley confiere a la industria eléctrica podría hacer de la negociación una mera simulación pues, al final de cuentas, impone a los propietarios de los terrenos la obligación de cederlos. Al denominarla "de utilidad pública" la ley ya ha dictado que la industria tiene prelación sobre el uso de los terrenos sobre cualquier otro, aunque la vida y sustento de los pobladores dependa de ellos. ${ }^{30}$ Por estas razones, las negociaciones se desarrollarán bajo condi-

${ }^{30}$ El artículo 71 de la Ley de la Industria Eléctrica dice lo siguiente: "La industria eléctrica se considera de utilidad pública. Procederá la ocupación o afectación superficial o la constitución de servidumbres necesarias para prestar el Servicio Público de Transmisión y Distribución de Energía Eléctrica, y para la construcción de plantas de generación de energía eléctrica en aquellos casos en que, por las características del proyecto, se requiera de una ubicación específica, conforme a las disposiciones aplicables. Las actividades de transmisión y distribución de energía eléctrica se consideran de interés social y orden público, por lo que tendrán preferencia sobre cualquier otra que 
ciones de presión sustancial sobre los propietarios; resultado de una reforma con un fuerte enfoque del desarrollo económico de la industria y una baja ponderación de la cuestión social.

\section{Conclusiones}

El objetivo del artículo fue analizar y demostrar las fallas en la regulación que han detonado y agravado la crisis social entre los habitantes rurales y una empresa operadora del Corredor Eólico del Istmo de Tehuantepec, en el estado de Oaxaca. De manera complementaria, se sostuvo como hipótesis que estas fallas tienen su origen en la falta de una ponderación de las cuestiones sociales en los instrumentos de regulación de los proyectos eólicos. En este sentido, se puso en evidencia que la ausencia de una internalización de las variables sociales ha causado la detonación de los conflictos entre comunidades y empresas.

Recientemente, los miembros de la APPJ volvieron a cerrar el camino hacia las obras de Bii Hioxo, así que es previsible que su conclusión no esté libre de más vicisitudes (Radio Fórmula, 2013). La situación de la empresa es apremiante: por tener infraestructura e inversiones hundidas, de alguna forma son rehenes de un país con un marco institucional en el que los grupos que deben convivir se repelen. La falta de acceso al polígono donde se encuentran las obras, en su parte sur, bien podría encarecer sustancialmente los costos del proyecto, al grado de desarticularlo económica y financieramente.

A la luz de lo analizado en este trabajo, el riesgo de que el proyecto de Bií Hioxo no prospere, o cualquier otro de su índole, se debe a que, en primer lugar, los instrumentos de planeación muestran un desfase importante entre los objetivos de atracción de la inversión y aquellos relacionados con el mejoramiento de las condiciones de vida de las comunidades de las regiones donde predomina la población indígena. De ahí que la legislación subsecuente, incluyendo la que acaba de entrar en vigor, muestre deficiencias importantes en cuanto a su capacidad de conciliar las necesidades de las comunidades rurales con la inserción de proyectos de menor impacto ambiental y tecnológicamente novedosos.

En este orden de ideas, la Subsecretaría de Electricidad, tras una serie de visitas al Istmo de Tehuantepec (Juchitán Informa, 2013), formó un grupo de trabajo para conciliar la obligación de consulta pública a las comunidades con la introducción segura de proyectos eólicos en esta 
zona. ${ }^{31}$ Tras meses de debate de la reforma energética, lo que se consiguió fue tan sólo incluir en la Ley de la Industria Eléctrica la obligación de la ya mencionada Manifestación de Impacto Social, cuya regulación consiste en tres artículos que establecen, a muy grandes rasgos, sus requisitos de forma y sustancia. Con una regulación tan laxa, esta Manifestación podría convertirse en una mera formalidad. ${ }^{32}$

El momento podría haber sido idóneo para enderezar las fallas regulatorias pues la reforma energética podría traer consigo un cambio profundo en la regulación social de la industria eléctrica. Esta reforma ofrecía un espacio de reflexión y cambio en el sentido de los proyectos privados de generación eléctrica, no únicamente con fines de atraer inversión, reducir impactos ambientales sino también para crear las obligaciones e incentivos a fin de que la iniciativa privada extendiera los beneficios de los proyectos más allá de la obtención de una contraprestación por el uso de las tierras.

En lugar de establecer únicamente contraprestaciones en efectivo, la Ley de la Industria Eléctrica podría haber consignado obligaciones de desarrollo social, conforme a las mejores prácticas internacionales. También podría haber provisto directrices más claras y eficaces para entablar el diálogo entre desarrolladores, comunidades y gobiernos locales. De esa forma podrían haberse dado las condiciones que han minimizado las fricciones como la construcción de una relación confianza entre empresas y comunidades basada en el respeto a nociones de justicia distributiva.

Es previsible que las comunidades no aprueben la instalación de infraestructura que en nada los beneficie, salvo la obtención de un precio por sus tierras. Y del análisis de la reforma constitucional y legal no se deduce de qué forma un mercado mayorista de generación eléctrica podría beneficiar a los pequeñísimos usuarios, quienes tal vez ni electrificación tengan. Esta es una buena razón para que las organizaciones se resistan al

${ }^{31}$ Conforme a la sentencia A.R. 631/2012 La consulta debe ser previa. Debe realizarse durante las primeras etapas del plan o proyecto de desarrollo o inversión o de la concesión extractiva y no únicamente cuando surja la necesidad de obtener la aprobación de la comunidad. Debe ser culturalmente adecuada. El deber estatal de consultar a los pueblos indígenas debe cumplirse de acuerdo con sus costumbres y tradiciones. Debe ser informada. Los procesos de otorgamiento exigen la provisión plena de información precisa sobre la naturaleza y consecuencias del proyecto a las comunidades consultadas, antes de y durante la consulta. Y debe ser de buena fe, con la finalidad de llegar a un acuerdo. Se debe garantizar, a través de procedimientos claros de consulta, que se obtenga su consentimiento previo, libre e informado para la consecución de dichos proyectos (SCJN, 2012: 84-85).

${ }^{32}$ El artículo 120 de dicha Ley se limita a decir lo siguiente: "Los interesados en obtener permisos o autorizaciones para desarrollar proyectos en la industria eléctrica deberán presentar a la Secretaría una evaluación de impacto social que deberá contener la identificación, caracterización, predicción y valoración de los impactos sociales que podrían derivarse de sus actividades, así como las medidas de mitigación correspondientes. La Secretaría emitirá el resolutivo y recomendaciones que correspondan, en los términos que señalen los reglamentos de esta Ley" (Ley de la Industria Eléctrica, 2014). 
cambio institucional y ello redunde en condiciones de inseguridad para la inversión.

En consecuencia, el eco de esta crisis social ya ha resonado más allá de los problemas del uso del suelo y vuelve a poner en tela de juicio la regulación de las figuras de inversión privada del sector eléctrico en México. En este trabajo se espera haber analizado con claridad una crisis que se manifiesta a partir de la resistencia de las comunidades a las reglas para la implantación de los proyectos eólicos en México; pero también de la omisión de los desarrolladores a seguir las reglas de inclusión de las comunidades. Es momento de poner atención en estas divergencias si el objetivo de la nueva política energética es el desarrollo incluyente, como lo indica la reforma constitucional.

\section{Fuentes consultadas}

AMDEE (Asociación Mexicana de Energía Eólica) (2012), "Iniciativa para el desarrollo de las energías renovables en México: Energía eólica", Gobierno Federal-Sener <http://www.amdee.org/presentaciones-amdee>, 30 de enero de 2016.

AMDEE (Asociación Mexicana de Energía Eólica) (2010), Panorama general de la energía eólica en México, <http://www.amdee.org/ Amdee/AMDEE_presentacion_esp.pdf>, 30 de enero de 2016.

APPJ (Asamblea Popular del Pueblo Juchiteco) Asamblea de los Pueblos Indígenas del Istmo de Tehuantepec en defensa de la tierra y el territorio, <http://tierrayterritorio.wordpress.com/>, 30 de enero de 2016.

Asociación Empresarial Eólica (2013), "Eólica en México: parque eólico de Gas Natural Fenosa", Revista Eólica y del Vehículo Eléctrico, Asociación Empresarial Eólica, Madrid, <http://www.evwind. com/2013/05/25/eolica-en-mexico-parque-eolico-de-gas-naturalfenosa-3/>, 13 de octubre de 2013.

Baxter, Jamie, Rakhee Morzaria y Rachel Hirsch (2013), “A case-control study of support/opposition to wind turbines: Perceptions of health risk, economic benefits, and community conflict", Energy Policy, núm. 61, Elsevier, pp. 931-943. 
Bidwell, David (2013), "The role of values in public beliefs and attitudes towards commercial wind energy", Energy Policy, núm. 58, Elsevier, pp. 189-199.

Borja Díaz, Marco A. (2003), "Proyecto eólico", Boletín IIE, Tendencia tecnológica, Instituto de Investigaciones Eléctricas, Cuernavaca, pp. 124-133.

Cámara de Diputados del H. Congreso de la Unión (2014), Ley de la Industria Eléctrica, <http://www.cfe.gob.mx/ConoceCFE/1_ AcercadeCFE/MarcoLegalyNormativo/Lists/Leyes1/Attachments/26/Leydelaindustriaelectrica1 1ago.pdf>, 17 de octubre de 2014 .

Cámara de Senadores del Congreso de la Unión (2013), Iniciativa de Decreto Presentado por el poder Ejecutivo Federal por el que se reforman los artículos 27 y 28 de la Constitución Política de los Estados Unidos Mexicanos, México, <http://www.presidencia. gob.mx/wp-content/uploads/2013/08/2013-08-12-Iniciativa-08001.pdf>, 28 de diciembre de 2013.

Cámara de Diputados, Comisión de Energía de la LXI Legislatura (2009), Dictamen de la Comisión de Energía, respecto a la iniciativa que modifica y adiciona diversas disposiciones de la ley para el aprovechamiento de energías renovables y el financiamiento de la transición energética, y modifica el artículo 36 bis de la ley del Servicio Público de Energía Eléctrica, Camara de Diputados, México.

Cámara de Diputados del H. Congreso de la Unión (2008), Ley para el Aprovechamiento de Energías Renovables y el Financiamiento de la Transición Energética (LAERFTE), <http://www.diputados.gob. mx/LeyesBiblio/pdf/LAERFTE.pdf>, 30 de septiembre de 2014.

Cámara de Diputados del H. Congreso de la Unión (1975), Ley del Servicio Público de Energía Eléctrica, <http://www.diputados. gob.mx/LeyesBiblio/abro/lspee/LSPEE_abro.pdf>, 23 de septiembre de 2013.

Centro de Estudios Espinosa Yglesias (2010) (coord.), Evaluación del desempeño de los órganos reguladores en México, <http://www.ceey. 
org.mx/site/files/organosreguladores2010ceey.pdf>, 30 de enero de 2016.

Colectivo KoLibrI (2013), Somos viento: Resistencia en el Istmo contra el proyecto eólico de Mareña Renovables (grabación de video), <http:// tierrayterritorio.wordpress.com/2013/04/24/video-somos-vientodel-colectivo-kolibri/>, 30 de enero de 2016.

Comisión para el Diálogo con los Pueblos Indígenas de México (2013), La energía eólica en México. Una perspectiva social sobre el valor de la tierra, <http://www.cdpim.gob.mx/v4/pdf/eolico.pdf>, 30 de enero de 2016.

Comisión Reguladora de Energía (2008), Resolución No. RES/372/2008. Resolución por la que se otorga a Fuerza y Energía Bií Hioxo, S. A. de C. V., permiso para generar energía eléctrica, bajo la modalidad de autoabastecimiento, Asociación Mexicana de Energía Eólica, México.

Cortés-Campos, Josefina (2007), Derecho administrativo y sector eléctrico, Porrúa-Instituto Tecnológico Autónomo de México, México.

Cortés-Campos, Josefina (s/f), El marco normativo de la utilización de las energías renovables, en prensa.

Chavance, Bernard (1990), "Formal and informal institutional change: The experience of postsocialist transformation", The European Journal of Comparative Economics, 5 (1), Università Carlo Cattaneo, Castellanza, pp. 57-71.

De la Vega-Navarro, Ángel (2011), "Energía y desarrollo en México. Necesidad de una nueva reflexión en el contexto de la crisis actual", en Jorge Flores Valdés (ed.), Panorama energético de México, Consejo Consultivo de Ciencias-Presidencia de la República, México, pp. 251-268.

Deloitte Youche Tohmatsu Limited (2009), Responsabilidad social empresarial y sustentabilidad. Un enfoque de riesgo y valor para el siglo XXI, Chile, Deloitte Chile, <http://oportunidades.deloitte.cl/ marketing/Deloitte_News_PuertoMontt/RSE-Sustentabilidad. pdf>, 30 de enero de 2016 . 
Diario Oficial de la Federación (2008), Decreto por el que se aprueba el Programa Sectorial de Energía (2007-2012), <http://www.cnh. gob.mx/_docs/8_Programa.pdf>, 10 de octubre de 2013.

Diario Oficial de la Federación (2002), Decreto por el que se aprueba el Programa Sectorial de Energía (2001-2006), <http://legismex. mty.itesm.mx/progs/p-Energia-02.pdf>, 10 de octubre de 2013.

El Economista (2013), "Suspenden actividades mineras en Wirikuta, México", <http://eleconomista.com.mx/sociedad/2013/09/12/ suspenden-actividades-mineras-wirikuta>, 1 de noviembre de 2013.

Gaceta Parlamentaria, Número 3757-X (2013), Punto de Acuerdo del Partido de la Revolución Democrática de la Cámara de Diputados, por el que se exhorta al gobierno de Oaxaca a intervenir en la solución del conflicto entre ejidatarios del istmo de Tehuantepec y empresas eólicas, a cargo del diputado Roberto López Suárez, México, 25 de abril de 2013.

Gaceta Parlamentaria, Número 3445-IV (2012), Iniciativa que reforma el artículo 36 de la Ley del Servicio Público de Energía Eléctrica, a cargo del diputado César Francisco Burelo Burelo, del Grupo Parlamentario del PRD, México, 7 de febrero de 2012.

Gas Natural Fenosa (2013), "Cronología e intereses de actores locales", Fundación Gas Nartural Fenosa, Juchitán, Oaxaca.

Gas Natural Fenosa (2012), "La perspectiva del promotor y gestor de parques eólicos", Fundación Gas Nartural Fenosa, <http://www. fundaciongasnaturalfenosa.org/SiteCollectionDocuments/Actividades/Seminarios/Merida\%202012\%2005\%2030/5.\%20Javier\%20Serrano.pdf>, 30 de enero de 2016.

Groth, Theresa M. y Christine Vogt (2014), "Rural wind farm development: Social, environmental and economic features important to local residents", Renewable Energy, vol. 63, Elsevier, pp. 1-8.

Hall, Nina, Peta Ashworth, y Patrick Devine-Wrig (2013), "Societal acceptance of wind farms: Analysis of four common themes across Australian case studies", Energy Policy, vol. 58, Elsevier, pp. 200-208. 
Inegi (Instituto Nacional de Estadística y Geografía) (2010), Marco geoestadístico municipal 2010, versión 5.0, Inegi, <http://cuentame.inegi.org. $\mathrm{mx} / \mathrm{mapas} / \mathrm{pdf} /$ nacional/coordenadas/coord-bynn.pdf>, 20 de enero de 2016.

Informes SiPaz (2013), ENFOQUE: Impactos y afectaciones de los proyectos de energía eólica en el Istmo de Tehuantepec, <http://www.sipaz. org/enfoque-impactos-y-afectaciones-de-los-proyectos-de-energia-eolica-en-el-istmo-de-tehuantepec/>, 12 de enero de 2014.

Juchitán Informa (2013), "Pedirá Oaxaca que SENER destrabe parque eólico", <http://juchitaninforma.blogspot.mx/2013/02/pediraoaxaca-que-sener-destrabe-parque.html>, 12 de noviembre de 2013.

Molina-Ruiz, José y Ma. Luz Tudela-Serrano (2008), “Elección de criterios y valoración de impactos ambientales para la implantación de energía eólica”, Papeles de Geografía, núms., 47-48, Universidad de Murcia, Murcia, pp. 171-183.

Molina-Ruiz, José y Ma. Luz Tudela-Serrano (2006), "La percepción social de las energías renovables a través de una encuesta de opinión. Un caso práctico en localidades del noroeste murciano", Papeles de Geografía, núm. 44, Universidad de Murcia, Murcia, pp. 141-152.

Nahmad-Sitton, Salomón (2011), El impacto social del uso del recurso eólico. Informe final para el Consejo Oaxaqueño de Ciencia y Tecnología (COCyT) del Conacyt. Proyecto 123396, Centro de Investigaciones y Estudios Superiores en Antropología SocialCentro Públicos Conacyt, Oaxaca, <https://langleruben.files. wordpress.com/2014/06/1-informe-final-ec3b3lico.pdf>, 30 de enero de 2016.

Oceransky, Sergio (2009), "Wind conflicts in the Isthmus of Tehuantepec: The role of ownership and decision-making models in indigenous resistance to wind projects in Southern Mexico", The Commoner, a web journal for other values, vol. 13, pp. 203-222.

OIT (Organización Internacional del Trabajo) (1989), Convenio 169 Sobre pueblos indígenas y tribales en países independientes, <https://www.ilo.org/dyn/normlex/es/f?p=NORMLEX PUB: 
12100:0::NO:12100:P12100_INSTRUMENT_ID:312314: NO>, 17 de septiembre de 2013.

Radio Fórmula (2013), "Retoman integrantes de la APPJ barricada contra planta eólica en el Istmo", Grupo Fórmula, México, <http:// www.radioformula.com.mx/notas.asp? Idn=365577\&sURL=>' 24 de febrero de 2014 .

Rojas, José Antonio (2014), "Riesgos de la Reforma Energética, México", La Jornada, Opinión, 17 de agosto de 2014, México, <http:// www.jornada.unam. $\mathrm{mx} / 2008 / 12 / 07 /$ index.php?section=econom ia\&article $=028 \mathrm{a} 1$ eco $>, 8$ de diciembre de 2013 .

Sánchez-Camacho, Alejandro (2007) (coord.), En defensa del patrimonio energético, Grupo Parlamentario del PRD, Cámara de Diputados, Congreso de la Unión, LX Legislatura, México.

SCJN (Suprema Corte de Justicia de la Nación) (2012), Amparo en Revisión 631/2012, Sentencia, <http://www.sitios.scjn.gob.mx/ codhap/sites/default/files/engrosepdf_sentenciarelevante/12006310.002-1712_0.pdf>, 17 de febrero de 2014.

Stark, Carlos (2001), Regulación, agencias reguladoras e innovación de la gestión pública en América Latina, CLAD-Naciones Unidas, pp. 1-67, <http://unpan1.un.org/intradoc/groups/public/documents/clad/clad0040204.pdf>, 30 de enero de 2016.

Stigka, Eleni, John Paravantis y Giouli Mihalakakou (2014), "Social acceptance of renewable energy sources: A review of contingent valuation applications", Renewable and Sustainable Energy Reviews, núm. 32, Elsevier, pp. 100-106.

Sutherland, LeeAnn y Kirsty Holstead (2014), "Future-proofing the farm: On-farm wind turbine development in farm business decisionmaking", Land Use Policy, núm. 36, Elsevier, pp. 102-112.

Zavala, Paola (2012), "El Istmo: violencia en vez de negociación", Nexos, México, <http://redaccion.nexos.com.mx/?p=3844\#sthash. MCvw69zD.dpuf>, 18 de septiembre de 2013. 
Miriam Grunstein-Dickter. Doctora en letras hispánicas y lusobrasileñas por la New York University, Nueva York. Profesora-investigadora de la Facultad de Derecho y Criminología de la Universidad Autónoma de Nuevo León. Licenciada en derecho por el Instituto Autónomo de México, miembro del Sistema Nacional de Investigadores, nivel I. Sus líneas de investigación son: Energía, regulación de servicios públicos, patrimonio público y proyectos de infraestructura. Imparte las materias: Seminario de regulación y Análisis jurídico para economistas en el Centro de Investigación y Docencia Económicas. Actualmente es investigadora asociada del Centro México del James Baker III Institute de Rice University. Entre sus publicaciones se encuentran: "Monopolios públicos y política de cambio climático en México. ¿Bastiones de cambio o barreras estratégicas?," en María del Pilar García Pachón (comp.), Minería, energía y medio ambiente, Universidad del Externado de Colombia, Bogotá, pp. 193-217 (2011). De la caverna al mercado. Una vuelta al mundo de las negociaciones petroleras. Análisis de concesiones y contratos de exploración y producción, Centro de Investigación para el Desarrollo, México (2010). "Pémex, la no empresa de todos los mexicanos. ¿Por qué Pémex no es una empresa pública y por qué debe serlo?”, Revista de Estudios Legislativos y de Opinión Pública, vol. 4, Cámara de Diputados, México, pp. 115-152 (2013). 